\title{
Hospital de Caridade São Pedro de Alcântara: assistência e saúde em Goiás ao longo do século XIX
}

São Pedro de Alcântara Charity Hospital: assistance and healthcare in Goiás during the nineteenth century

Sônia Maria de Magalhães

Mestre e doutoranda em história social pela UNESP - Franca

Av. São Vicente, 3371 bl. 2/31 Santa Rita

14403-720 Franca - SP Brasil

soniamariamagalhaes@bol.com.br 


\section{Introdução}

O Hospital São Pedro de Alcântara de Goiás foi fundado em 1825, sob a proteção de d. Pedro I, pela Carta Imperial de 25 de janeiro, para servir de abrigo aos enfermos pobres e indigentes. Vinculava-se às preocupações da Câmara de Vereadores e do governo da província em torno da função de curar por caridade os enfermos pobres. Acolhia desse modo dementes, doentes e necessitados, fossem eles homens livres ou escravos. Funcionava com um regulamento que, ao longo dos anos, passou por mudanças em decorrência das suas necessidades e das peculiaridades locais, como aquelas de caráter sanitário e higiênico presentes no novo estatuto de 1835.

O hospital recebia os desamparados mediante apresentação de um atestado de pobreza emitido pelo pároco ou pelo governo provincial (AHEG, caixa 0010). Permitia-se também o tratamento de escravos, desde que o senhor custeasse sua sustentação e a ação terapêutica. Atendia, a preços módicos, os soldados do exército sediados na província e igualmente os presos da cadeia pública.

O dispensário era 'socorrido' por um médico, um cirurgião e dois enfermeiros, um para a enfermaria masculina e outro para a feminina. Antigos pacientes que permaneciam no hospital compunham, na maioria das vezes, a equipe de enfermeiros que, além de alguma prática na área, deveria ter uma conduta bastante regular, saber ler, escrever e contar (AHEG, caixa 401). Porém, a maioria desse pessoal era completamente destituída de qualificação.

Ao internar-se, o paciente deixava tudo o que possuía na entrada, recebia três camisas, três calças, dois pratos, uma tigela, uma moringa e dois copos — um para água e outro, menor, para os remédios. O médico prestava atendimento aos pacientes algumas vezes por semana, ocasiões em que prescrevia a terapêutica, da qual se incumbiam os enfermeiros.

Os raros estudos que tratam do Hospital de Caridade São Pedro de Alcântara mostram-no como espaço privilegiado para o desenvolvimento das estratégias sanitárias e como estas interferiram em todo o espaço urbano da cidade de Goiás no século XIX (Moraes, 1995; Salles, 1999; Rabelo, 1997). Todavia não se observa nesses estudos uma análise mais apurada no sentido de esclarecer aspectos fundamentais do funcionamento e do serviço assistencial prestado à comunidade, único no gênero naquela província. Percebe-se que o estabelecimento possuía funções que suplantavam aquelas específicas do nosocômio, entendido como principal local de tratamento das doenças. Era diferente das casas de Misericórdia, em que o atendimento hospitalar era complementar, constituindo apenas 
uma de suas obras. ${ }^{1}$ Em Goiás, o hospital, como o eixo central no que se refe-re à assistência social, abarcava funções e princípios caritativos cristãos, recolhendo alienados, menores abandonados, assistindo aos encarcerados, doentes e necessitados e, posteriormente, enterrando gratuitamente os indigentes. Prestava amparo material e espiritual à comunidade na vida e na morte.

A instituição nasceu do desejo de um grupo local influente, que reconhecia um mal social: a ausência de assistência aos destituídos e enfermos. Cogitou-se inicialmente a possibilidade de colocá-lo sob a administração das Misericórdias, instituição de origem portuguesa que auxiliou de forma corporal e espiritual boa parte dos habitantes do Brasil. Entretanto, essa piedosa organização não se instalou em Goiás, pelo menos até a criação da nova capital do estado já no século XX (Freitas, 1999). Tal fato era previsível para o comandante das Armas Cunha Mattos², que desacreditava na instalação da Misericórdia em terra tão miserável como Goiás (AHEG, livro 119, p. 271).

Pode-se perceber, dessa forma, que nem sempre a sobrevivência de um hospital infere a existência das Misericórdias. Em Goa, Cochim e Cannanore, por exemplo, existiram hospitais desde os primeiros momentos da colonização portuguesa, muito antes da fundação das filiais respectivas da Misericórdia (Russel-Wood, 1981, p. 64).

O grupo local dominante em Goiás - representado por fazendeiros, administradores públicos, funcionários do governo e comerciantes - empreendeu um árduo trabalho no sentido de comover as pessoas, especialmente as mais abastadas, para contribuir, por meio de doações e esmolas, na edificação de uma instituição local que acudisse a pobreza desamparada. O bispo Francisco Ferreira de Azevedo, da Prelazia de Goiás e integrante do Conselho da Província, apoiou-se no capítulo 15 do Deuteronômio para convencer e incitar as suas ovelhas sobre a importância da compaixão e da doação de esmolas, "uma vez que a esmola é um escudo contra a morte e um perdão para o pecado, serão confiados quarenta dias de verdadeira indulgência na forma da Igreja a todos aqueles que concorrerem para a fun-dação e conservação do sobredito hospital" (SCFD, carta pastoral, 11.4.1825).

Centenas de pessoas provenientes das mais distantes áreas daquele território contribuíram com esmolas e doações em dinheiro ou espécie, inclusive o cético Raymundo José da Cunha Mattos, que ofertou 150 mil-réis. O comandante Joaquim Alves ${ }^{3}$, grande empreendedor de Meia Ponte, ofereceu de seu próprio bolso cinquenta mil-réis e depois mais 41 mil-réis, como resultado das esmolas que arrecadou entre os moradores da localidade. Um carregamento de salsaparrilha avaliado em dez mil-réis também foi oferecido em benefício do estabelecimento (AHEG, livro 145). 
No Brasil, a caridade motivou atos e atitudes e incentivou a criação de inúmeras associações beneficentes, quando inexistia outra solução para o problema da pobreza que não fosse o apelo à generosidade dos mais ricos com relação aos desvalidos. Para Beatriz Weber (1999), a religiosidade é um elemento característico da sociedade brasileira. Para os católicos, participar das associações religiosas era parte fundamental da sociabilidade cotidiana: "nessa religiosidade, a imagem de Deus apresentava expressões específicas numa sociedade marcada pela escravidão. Deus apresentavase como Pai, aproximando da imagem do senhor dono de escravos, que exercia poder de vida e morte sobre seus dependentes" (idem, ibidem, p. 135). Assim, a esse senhor proprietário que era o provedor só valeria a prece, a intercessão, jamais a rebeldia e a desobediência.

A caridade, nesse sentido, tinha a função de preservar o contexto paternalista, por meio da concessão de donativos. Estes, todavia, eram inacessíveis aos escravos, mesmo que eles fossem atendidos pelas organizações de caridade - a conta do tratamento, como já foi mencionado, era custeada pelo senhor. Ademais, praticar filantropia consistia em uma forma de exteriorizar a riqueza, pois no Brasil a religião suplantava a importância de algo a ser cumprido; cabia que seu cumprimento fosse visto (Russel-Wood, op. cit.).

Ao longo do tempo, o São Pedro de Alcântara assumiu os serviços de assistência específicos das Misericórdias, tais como o de auxílio aos pobres, aos presidiários e aos morféticos, além da responsabilidade dos enterros na capital.

\section{A sustentação financeira}

A saúde pública no Brasil sempre foi relegada ao segundo plano (Bertolli Filho, 2000). A responsabilidade pelas medidas sanitárias domésticas cabia a cada morador individualmente. No período colonial, esta questão pertencia ao Conselho Municipal e, em menor grau, às autoridades da Coroa. De 1828 a 1850 os serviços de saúde pública ficaram a cargo dos municípios. As Câmaras deliberariam em geral sobre os meios de promover e manter a tranqüilidade, a segurança, a saúde e a comodidade dos habitantes. De 1850 a 1889, a concentração fez-se pela criação de órgãos centrais de saúde pública, seguida posteriormente de organismos provinciais e municipais subordinados a um órgão principal, tendo as municipalidades o direito de legislar sobre a saúde pública (Lyda, 1994, p. 28). A partir de 1828, os serviços hospitalares passaram a ser de responsabilidade das Câmaras, porém, estas se mostraram incapazes para o exercício de tal atividade (Leal, 1975, p. 75), em decorrência sobretudo da falta de verbas. No Brasil, as irmandades abarcaram 
essas funções. A Misericórdia, por exemplo, desempenhava papel único na manutenção de hospitais públicos nas cidades e vilas.

O hospital de Goiás cumpriu esse papel como por 'milagre', nos primeiros anos de sua criação, graças às doações e às esmolas oferecidas pelas pessoas mais abastadas da província. Pelo decreto de 10 de julho de 1832, o governo imperial dotou-o com a quantia de um conto e 200 mil-réis anuais, único rendimento para custear seus dispêndios, pois o diminuto lucro da botica cobria apenas as despesas dos remédios que se aplicavam aos pobres (Memórias Goianas, no 3, 1986, p. 26). A venda de medicamentos a prazo, que tanto onerava o cofre da instituição, foi proibida em 1848 (AHEG, livro 202, p. 11).

$\mathrm{Na}$ opinião do presidente da província Luiz de Camargo Fleury ${ }^{4}$, a receita do hospital melhoraria visivelmente se fosse concedido ao mesmo o privilégio exclusivo no comércio de drogas medicinais (Memórias Goianas, no 3, op. cit., p. 73). Assim, a dotação imperial e o possível lucro da botica correspondiam à sua receita ordinária. O ganho extraordinário provinha do atendimento prestado aos militares, dos serviços àqueles que podiam custear a terapêutica, a exemplo dos donos dos escravos, e de algumas módicas esmolas.

No caso dos escravos, garantia-se o atendimento hospitalar ao cativo por meio de um ajuste firmado entre o hospital e seu proprietário. No dia 28 de março de 1883, por exemplo, o escravo Joaquim foi internado, e seu dono teve de assinar o seguinte contrato padrão:

Eu, abaixo assinado João de Araújo Godinho, me obrigo a pagar o tratamento de meu escravo Joaquim que é recolhido a este estabelecimento, natural desta cidade, com 30 anos de idade, solteiro, a razão de 800 réis diário a contar desta data até a em que tiver alta ou falecer, e bem assim todos os medicamentos que se gastarem com o mesmo durante o tempo do seu tratamento.

Joaquim recebeu a terapêutica durante 25 dias, perfazendo um total de 45 mil e 830 réis. Como seu dono, João Godinho, reclamou dois dias cobrados a mais, a conta foi revista e os dias excedentes, abatidos.

A saúde do escravo era uma précondição na aferição de seu valor como mercadoria. Seu preço era determinado pela aparência geral, já que "escravo doente era escravo parado, escravo parado era prejuízo” (Leite, 1996, p. 163).

Mesmo sendo uma contribuição esporádica, os donativos e as módicas esmolas tinham importância, a exemplo das quantias de 20 mil-réis doadas pelo coronel Luiz Pinheiro Pinto Guimarães e a de 65 mil e 800 réis para auxílio da construção do novo prédio do hospital (AHEG, livro 202, pp. 19 e 20v). A extinta Companhia Comercial Mercantil do Araguaia também cedeu a benefício do São 
Pedro de Alcântara o direito que tinha em um dos seus barcos e a maior parte do carregamento que ficou na paragem de Juquiraproar, na província do Pará (idem, ibidem, pp. 27-28v).

No ano de 1835, a Câmara Municipal adquiriu pela quantia de quatrocentos mil-réis uma chácara para recolhimento dos infestados de morféia, lepra e chagas cancerosas, propriedade que foi integrada à administração do hospital. Porém a Câmara não fez a divisão das enfermarias masculina e feminina para iniciar o atendimento aos enfermos. Pouco tempo depois, há notícias de que o imóvel encontrava-se em ruínas e completamente abandonado. Mesmo nessas condições, alguns enfermos foram acolhidos (Memórias Goianas, nº 3, op. cit. p. 26). A maioria deles, contudo, continuava vagando pelas ruas, esmolando alimento e esperando pela morte.

O hospital recebeu ainda subvenção do governo provincial durante o Império: cem mil-réis para o atendimento dos lázaros e 14 mil e 620 réis para os presos da cadeia serem acudidos com alimentos e remédios (Moraes, op. cit., p. 140). Obteve autorização do governo para organizar planos e extrair loterias a fim de arrecadar verbas para organizar reformas ou novas construções. Pela lei provincial de 27 de julho de 1837, criou-se uma loteria com a dotação de quatrocentos mil-réis a seu proveito (Memórias Goianas, no 3, op.cit., pp. 109-10). Outra foi concedida em 1850, extraída na Corte, para adquirir bens de raiz até o valor de vinte mil-réis (Coleção das Leis do Império, 1850, p. 257).

Com a inauguração do cemitério público, em 1859, seguindo as normas de higiene que proibiram o enterro de cadáveres no interior dos templos religiosos, o hospital contou com mais um expediente financeiro, uma vez que os atestados de óbito e os serviços funerários passaram a ser de sua responsabilidade.

O nosocômio organizou-se com caráter público, com direito a receber esmolas ${ }^{5}$ e outros rendimentos para serem aplicados na ampliação do seu serviço social e nas benfeitorias do edifício. Em 1836, por exemplo, a falta de cômodos nas enfermarias era tamanha que havia "absoluta necessidade de dar-lhes maior expansão, unindo a cada uma delas aos quartos que são imediatos, para cujo fim era indispensável fazer alguma despesa" (AHEG, caixa 0010). Essa reforma foi aprovada e dela encarregou-se o administrador da instituição. Em 1842 o presidente da província José Assis Mascarenhas ${ }^{6}$ autorizou o tesoureiro interino do hospital a despender a quantia de 605 mil e 760 réis para construir uma nova cozinha e três quartos unidos a ela (AHEG, livro 202, pp. 2 e 3v). Entretanto, ao que parece, inviabilizaram-se essas obras, pois no dia 16 de março de 1848. 
O vice-presidente da província observando pessoalmente o estado em que se achava o Hospital de Caridade desta cidade, de ruínas, falta de asseio, e mesmo de cômodos para a separação dos sexos, falta de uma cozinha, e dos meios de obstar, que de fora introduzam nas enfermarias bebidas espirituosas, e comidas contrárias à dieta prescrita pelos médicos, deseja remediar a todos estes males, a benefício da humanidade, e reconhecendo na pessoa do atual administrador do mesmo hospital zelo, atividade, e inteireza, o encarregar das obras e reparos necessários, apresentando semanalmente as [ilegível], e conta da compra de materiais ao respectivo tesoureiro para as pagar: outro sim promova a arrecadação do que se deve ao Hospital para destarte se fazer face às despesas (idem, ibidem, p. 7v).

Os motivos pelos quais essas melhorias não foram efetivadas continuam obscuros, já que o recurso tinha sido aprovado. Sabese apenas que sua contabilidade deixava a desejar, pecava pela desorganização e ausência de clareza na relação entre a receita e a despesa. A movimentação contábil, contudo, apresentou vantagens nos anos de 1845 a 1846, quando o médico do hospital, Theodoro Rodrigues de Moraes, ${ }^{7}$ passou a administrá-la. Sua assiduidade e método no exercício de tal função mereceram elogios por parte do presidente da província, Joaquim Ignácio Ramalho (Memórias Goianas, no 4, 1996).

Na cidade de Goiás, os interesses da elite estavam representados pela junta de caridade que administrava o São Pedro de Alcântara (Moraes, op. cit.), composta por seis cidadãos abastados residentes na cidade e do juiz de fora (o presidente). Ao presidente da província cabia a nomeação dos membros conforme as determinações do regulamento de 1848, organizado pelo presidente Antônio de Pádua Fleury. ${ }^{8}$ Competia à junta administrar convenientemente os recursos, prestar contas ao diretor e ao boticário, pagar os empregados, estabelecer os honorários dos facultativos, escolher os empregados e expulsá-los quando se demonstravam incompetentes no desempenho das suas obrigações. Incumbia-se um dos membros a função de tesoureiro das rendas e a outro, a de escrituração. Esta comissão, porém, tinha de ser substituída a cada três meses, para se tornar alternadamente acessível a todos os componentes. Em decorrência da inexpressividade dos rendimentos, a tesouraria provincial custeava os salários dos integrantes da junta e de todos os empregados.

A situação financeira do hospital ao longo do Oitocentos está demonstrada no Quadro 1.

Ainda que a documentação impossibilite o acompanhamento pormenorizado do movimento financeiro do nosocômio desde a sua inauguração, possuindo ainda hiatos decorrentes da falta de informações, mesmo na época em que foi elaborado o inventário pouco se sabia sobre a sua sustentação. No ano de 1843, a admi- 


\section{Quadro I}

Orçamento financeiro do Hospital de Caridade São Pedro de Alcântara, 1835-1880 (valores em réis)

\begin{tabular}{|c|c|c|c|c|}
\hline Ano & Receita & Despesa & Saldo/Déficit & Fundo de Reserva \\
\hline 1829 & $3: 549 \$ 562$ & $3: 549 \$ 562$ & 0,000 & 0,000 \\
\hline 1835 & $1: 505 \$ 260$ & $935 \$ 237$ & $570 \$ 023$ & 0,000 \\
\hline 1836 & $2: 710 \$ 324$ & $2: 711 \$ 351$ & $-1 \$ 027$ & $?$ \\
\hline 1846 & $1: 229 \$ 815$ & $1: 140 \$ 240$ & $89 \$ 575$ & $?$ \\
\hline 1847 & $4: 380 \$ 830$ & $4: 318 \$ 114$ & $32 \$ 716$ & $14: 015 \$ 289$ \\
\hline 1848 & $3: 230 \$ 000$ & $3: 484 \$ 000$ & $-254 \$ 000$ & $15: 471 \$ 585$ \\
\hline 1849 & $5: 787 \$ 904$ & $5: 581 \$ 8531 / 2$ & $206 \$ 051$ & $18: 564 \$ 860$ \\
\hline 1850 & $4: 970 \$ 598$ & $4: 267 \$ 360$ & $703 \$ 238$ & $20: 001 \$ 727$ \\
\hline 1851 & $4: 151 \$ 781$ & $4: 080 \$ 116$ & $74 \$ 665$ & $30: 589 \$ 916$ \\
\hline 1852 & $4: 729 \$ 640$ & $4: 517 \$ 665$ & $181 \$ 974$ & $33: 160 \$ 761$ \\
\hline 1853 & $5: 615 \$ 424$ & $5: 719 \$ 193$ & $-730 \$ 861$ & $33: 348 \$ 933$ \\
\hline 1854 & $5: 565 \$ 120$ & $4: 895 \$ 120$ & $669 \$ 430$ & $28: 217 \$ 407$ \\
\hline 1855 & $7: 042 \$ 027$ & $6: 634 \$ 657$ & $407 \$ 370$ & $30: 512 \$ 381$ \\
\hline 1856 & $10: 582 \$ 097$ & $10: 441 \$ 731$ & $140 \$ 360$ & $?$ \\
\hline 1857 & $6: 551 \$ 160$ & $5: 708 \$ 990$ & $842 \$ 170$ & $?$ \\
\hline 1858 & $11: 069 \$ 563$ & $11: 069 \$ 563$ & $941 \$ 602$ & $?$ \\
\hline 1859 & $?$ & $?$ & déficit & $24: 318 \$ 406$ \\
\hline 1860 & $9: 342 \$ 861$ & $7: 920 \$ 668$ & $1: 422 \$ 193$ & $?$ \\
\hline 1867 & $?$ & $10: 158 \$ 468$ & $4 \$ 823$ & $?$ \\
\hline 1868 & $10: 331 \$ 520$ & $10: 458 \$ 158$ & $?$ & $?$ \\
\hline 1869 & $18: 119 \$ 798$ & $14: 076 \$ 924$ & $4: 042 \$ 874$ & $?$ \\
\hline 1870 & $23: 376 \$ 448$ & $18: 642 \$ 227$ & $4: 734 \$ 221$ & $?$ \\
\hline 1871 & $25: 368 \$ 809$ & $18: 140 \$ 403$ & $7: 228 \$ 406$ & $?$ \\
\hline 1872 & $34: 608 \$ 670$ & $23: 252 \$ 359$ & $11: 356 \$ 311$ & $?$ \\
\hline 1873 & $29: 638 \$ 190$ & $21: 159 \$ 750$ & $8: 478 \$ 440$ & $?$ \\
\hline 1874 & $31: 583 \$ 744$ & $15: 854 \$ 733$ & $15: 729 \$ 011$ & $38: 089 \$ 873$ \\
\hline 1875 & 29:110\$009 & $19: 137 \$ 700$ & $11: 282 \$ 723$ & $?$ \\
\hline 1876 & $35: 567 \$ 652$ & $17: 297 \$ 087$ & $16.270 \$ 565$ & $?$ \\
\hline 1877 & $?$ & $?$ & $575 \$ 088$ & $?$ \\
\hline 1878 & $14: 593 \$ 058$ & $14: 069 \$ 996$ & $523 \$ 062$ & $?$ \\
\hline 1879 & $20: 175 \$ 284$ & $19: 969 \$ 994$ & $1: 205 \$ 290$ & $?$ \\
\hline 1880 & $20: 387 \$ 103$ & $11: 088 \$ 960$ & $9: 298 \$ 143$ & $?$ \\
\hline
\end{tabular}

Fontes: Memórias Goianas no 3; Jornal Matutina Meiapontense (CD-ROM), 7.8.1830, pp. 234-5; AHEG, Documentos avulsos, 1836, caixa 0021; Relatórios políticos, administrativos, econômicos, sociais etc. dos governos da província de Goiás (1835-1843), Goiânia, UCG, 1986; Memórias Goianas, $\mathrm{n}^{\circ} 4$ (1845-1849), 1996; no 5 (1850-1852), 1996; nº 7 (18561859), 1997; no 8 (1859-1863), 1997; no 9 (1862-1863) 1998; no 10 (1864-1869),1998; no 11 (1870-1874) 1999; no 12 (1875-1879), 1999; no 13 (1880-1881), 2001; nº 14 (18821889), 2001. 
nistração provincial mandou organizar um balanço da receita e despesa desde a sua concepção, visando a implantação de um novo regulamento compatível com suas novas exigências (Memórias Goianas, no 3, op. cit.). Em 1846, em decorrência da sua grande desordem, ainda não tinha sido possível avaliar a sua real condição, conforme mencionou o presidente de província Joaquim Ignácio de Ramalho. ${ }^{9}$ Declarava ele que

... todos os esforços que tenho empregado para conseguir tem sido inúteis; contudo espero ainda estabelecer regularidade, fiscalização, e economia neste estabelecimento para que possa produzir algumas das vantagens, que se pode esperar da sua fundação (Memórias Goianas, nº 4, 1996, pp. 33-6).

Parece que a avaliação realizada surtiu algum efeito, pois em 1847 já era possível notar os efeitos positivos da vistoria. Além de a receita suplantar a despesa, obteve-se ainda um saldo de 32 mil e 716 réis e a constituição de um fundo de reserva no valor de 14.015 mil e 289 réis, como pode ser notado no Quadro 1.

Em 1848 o Hospital de Caridade São Pedro de Alcântara passou a ser regido pelo Regulamento Provincial no 1 , de 5 de setembro do mesmo ano, que reduziu o número de componentes da junta administrativa de seis para cinco membros.

Embora os efeitos desses novos tempos pudessem ser averi-guados na contabilidade mais organizada, os recursos disponíveis para o hospital eram irrisórios diante de suas imensas necessidades. A situação piorou em 1849, época em que o hospital quase fechou as portas em razão do atraso do repasse da dotação provincial decorrente da sua inexpressiva arrecadação. Nessa circunstância, a solução foi recorrer mais uma vez ao expediente das esmolas,

... e algumas obteve da Munificência de Sua Majestade o Imperador $500 \$ 000$ réis e da filantropia de vários cidadãos goianos \$700 réis, para melhorar a sorte do estabelecimento à seu cargo, dirigiu representações à Assembléia Geral Legislativa, pedindo o auxílio de uma loteria e a concessão para adquirir o dito hospital até 20:000\$000 de réis em bens de raiz ${ }^{10}$ (Memórias Goianas, nº 5, 1996, p. 57).

Mesmo gerenciando um precário orçamento, piorado pelos atrasos no repasse da dotação provincial, a junta diretora conseguia a duras penas administrar o nosocômio, graças ao deferimento do pedido de auxílio de uma loteria para as obras do hospital e a competência para possuir bens de raiz até a quantia de 20 contos de réis. Os administradores pretendiam aplicar parte desse recurso na construção de um novo hospital em local que melhor preenchesse as condições higiênicas para seu estabelecimento.

No decurso de cinco anos, a diretoria conseguiu expressivos resultados, como o de elevar o patrimônio de 14 mil a mais de 33 
mil réis (ver Quadro 1). Diante de tão florescente situação, a Assembléia Provincial resolveu cercear um terço da dotação que concedia ao hospital. Propôs ainda, em decorrência dos seus limitados recursos financeiros, que os membros da junta deixassem de lado momentaneamente o projeto de fundação de um novo dispensário, presente no novo regulamento, e direcionassem seus esforços, primeiramente, para a construção de um cemitério na capital (Memórias Goianas, no 6, 1997, pp. 44-5).

A documentação arrolada não permite o acompanhamento das negociações realizadas por parte do governo e da cúpula administrativa do hospital, diante das divergências de interesses. Todavia no ano de 1856, estando de acordo com a junta de caridade, o governo provincial resolveu mandar edificar um cemitério para fazer cessar os enterramentos nos templos da capital. Com a inauguração do almocave em 1859, o São Pedro de Alcântara passou a contar com mais um rendimento proveniente dos serviços funerários.

Um outro ponto de discordância entre a administração hospitalar e o governo provincial girava em torno do pagamento de taxas e impostos. Em 21 de fevereiro de 1850, por exemplo, a junta de caridade encaminhou um ofício ao governo provincial solicitando que sua botica fosse aliviada do imposto de 12 mil e 800 réis naquele ano. A resposta favorável veio em poucas semanas (Memórias Goianas, no 4, op. cit.). Em 1856, novamente foi feito o pedido de isenção ao governo, porém este pediu um comprovante demonstrando a indigência da instituição para que ele fosse concedido (AHEG, livro 202, p. 33). O mesmo aconteceu com a solicitação de imunidade do imposto do correio em 1854 (idem, ibidem, pp. $15 \mathrm{v}$ e 16). Apesar de o governo provincial subvencionar o hospital, percebe-se uma certa suspeita de sua parte em relação ao caráter filantrópico da instituição, já que suas rendas cresciam substancialmente. A dúvida estava presente também no relatório do presidente da província José Martins Pereira de Alencastre ${ }^{11}$, no ano de 1862, no qual ele mencionava diversas irregularidades referentes à gestão administrativa da fundação. Em relação ao seu funcionamento, Alencastre observava que "a sua gestão à parte explica o motivo de estar até hoje este ramo de serviço inteiramente fora das vistas da tesouraria, ... que sendo próprio da província, bem como o seu patrimônio, não há razão para que esteja fora das vistas da repartição fiscal" (Memórias Goianas, no 9, 1998, p. 41). Sugeria ainda a criação de uma irmandade que tomasse conta do hospital e promovesse seu desenvolvimento, uma vez que o governo não dispunha de recur-sos para a área de saúde.

A chegada das irmãs dominicanas, em 1889, abriria novas possibilidades para a saúde e a educação em Goiás. O fato de a província não dispor de recursos para investir na educação fez com que o governo estimulasse a iniciativa privada na instrução. A fundação 
do Colégio Santana pelas dominicanas confirma que a legislação dava ampla liberdade à iniciativa particular no ensino (Canezin et al., 1994, p. 44). Além do colégio, a congregação teria a seu cargo, na capital, a direção interna do Asilo de São Vicente e do Hospital São Pedro de Alcântara ( Informação Goyana), que passou por uma grande reforma em 1908, verdadeira reconstrução orçada em 87.252 mil e 450 réis. A junta administrativa, composta por monsenhor Confúcio (provedor), Joaquim de Santana Andrade (tesoureiro) e Antônio Augusto de Carvalho (secretário), adquiriu ainda o prédio contíguo para a residência das irmãs de caridade que trabalhavam no local (Curado, 1989). Novas benfeitorias, sintonizadas, na medida do possível, com as concepções modernas das instituições de saúde, foram realizadas em 1921, como a construção de outras enfermarias, maternidade e bloco cirúrgico (Salles, op. cit., p. 92).

Ao longo do Oitocentos, apesar das divergências ocasionais entre o governo provincial e a junta administrativa no que tangia à gestão dos recursos, estes continuaram a ser repassados, já que o hospital era a única entidade que prestava assistência aos doentes e desamparados.

\section{O atendimento hospitalar}

É comum encontrar nos relatórios dos presidentes da província de Goiás referências aos serviços humanitários prestados pelo hospital, como asilo e abrigo de infelizes, indicando-se uma relação mais precisa com a caridade do que com a medicina. As peculiaridades sobre o funcionamento dos hospitais no século XIX podem ser mais satisfatoriamente compreendidas ao investigarmos suas origens e a maneira como eles foram estabelecidos na Europa.

A filantropia social em Portugal, em sua forma mais primitiva, se originara nas albergarias, ou hospedarias, situadas nas rotas de peregrinos já no século XI. Algumas delas, mais tarde, se transformaram em hospitais. Empregava-se a palavra 'hospital' como sinônimo de 'albergaria', mas nem sempre isso significava assistência médica, pois o grau de beneficência social variava de uma hospedaria para a outra (Russel-Wood, op. cit, p. 6).

Os hospitais serviram de asilos para os enfermos, estropiados e miseráveis e de albergue para os peregrinos. Acolhiam em primeiro lugar as pessoas materialmente degradadas. Assim, se um abastado recorresse a essa instituição, sabia com conhecimento prévio que nela encontraria a multidão dos verdadeiros miseráveis dependentes da caridade (Geremek, 1986, pp. 36-7). As organizações de atenção às doenças continuaram preferencialmente devotadas aos desprovidos e atenderam não apenas a enfermos, mas também a vítimas de toda sorte de infortúnios, que despendiam não só de serviços médicos mas de cuidados gerais e assistência social (Antunes, 1991, pp. 129-30). 
Percebe-se, assim, que o exercício da medicina continuou a se desenvolver de modo independente dos hospitais. Por meio de outros mecanismos, como o ensino nas universidades, a cobrança de honorários e a prestação direta de serviços àqueles que podiam arcar com essas despesas, seus praticantes empenhavam-se na institucionalização da medicina. Para Rosen (1994) a introdução da medicina profissional nos recintos hospitalares, a redefinição de seu perfil institucional, a especificação de suas atribuições terapêuticas e o aproveitamento racional dos recursos disponíveis propiciaram a gradual conversão do hospital geral - que emergia da secularização das entidades cristãs de atenção às doenças — nos estabelecimentos de saúde dos nossos dias.

Esses avanços viriam a constituir os hospitais contemporâneos, representados, em um primeiro momento, pelos novos conhecimentos anatômicos produzidos pela dissecação humana e pela descoberta da circulação do sangue, a qual fornecera a base teórica para o estudo do corpo como sistema funcional. Posteriormente foram impulsionados pelo emprego anestésico de diferentes substâncias, como o éter, que favoreceram o progresso das práticas cirúrgicas. Por outro lado, não se pode deixar de mencionar que o mercantilismo, o despotismo esclarecido, a iniciativa privada e a ação cooperativa convergiram para fazer do hospital o elemento central da prestação de serviços médicos, objetivo só plenamente atingido no final do século XIX (idem, ibidem).

Foucault $(1987,1994)$, por sua vez, chama atenção para um fator eminente-mente político: a introdução de mecanismos disciplinares visando a ordenar o espaço confuso dos hospitais. Ele descreve a disciplina como uma tecnologia do exercício do poder, de gestão dos homens, uma arte de distribuição espacial dos indivíduos que implica o controle sobre o desenvolvimento de suas ações, o registro contínuo dos seus atos, a vigilância perpétua de cada pessoa. Aponta a dimensão clínica das novas idéias e teorias médicas, abordando-as de modo aplicado ao contato individualizado do médico com o doente.

Também nesse âmbito a medicina pautou-se por uma coor-denada espacial e creditou efeito terapêutico às ações visando à salubridade do meio que envolve o doente. Tanto quanto a aplica-ção farmacêutica e cirúrgica, atribuía-se agora um potencial curativo ao ar que os doentes respiravam, à água com que eram banhados, à temperatura ambiente, às vestimentas em geral, ao regime alimentar a que eram submetidos (Foucault, 1987). Ao gestar essa nova sabedoria médica, seus partidários teriam perce-bido que os hospitais, uma vez disciplinados às suas rotinas, poderiam vir a ser o lugar ideal para a constituição de microcosmos terapêuticos nos quais inserir os doentes e sobre eles agir (idem, 1994). 
O nosocômio da cidade de Goiás apresentava as características de um hospital/asilo. A especialização em terapêutica só ocorreria, ao que tudo indica, no início do século XX.

Apesar da ausência de informações concernentes a alguns anos, o Quadro 2 expõe os aspectos do movimento das enfermarias e do atendimento hospitalar no período de 1829 a 1880.

Mesmo existindo várias lacunas, a documentação examinada permite visualizar aspectos do atendimento prestado pelo dispensário aos goianos. Por volta de 1819, Goiás abrigava 68.489 habitantes, e a capital, centro administrativo regional, resguardava o maior contingente populacional, estimado em 14.251 habitantes, sendo 11.178 livres e 3.073 escravos (Funes, 1986). ${ }^{12}$

A falta de leitos consistiu, ao longo dos anos, em um grande problema do hospital. O edifício possuía capacidade para nele serem tratados 34 enfermos, sendo trinta do sexo masculino e quatro do feminino (Memórias Goianas, no 9, op. cit., p. 41). Como a demanda era maior que a oferta, socorria-se a maioria dos mazelados com víveres e medicamentos em domicílio, a exemplo de Felisberta Roiz da Silva, que recebeu remédios e alimentos necessários para ser tratada em casa (AHEG, livro 202, pp. 24v e 26v).

$\mathrm{O}$ atendimento na residência diminuía o acúmulo de eivados no recinto e disponibilizava leitos para aqueles que podiam pagar pelo tratamento. Destarte, por causa da difícil situação financeira, o hospital passou a receber cada vez mais soldados e pessoas que podiam custear o tratamento por ajuste. Assim, a caridade para com os pobres, função primeira da instituição, foi relegada a segundo plano.

Em relação à capacidade de acomodação de enfermos no recinto, o médico Francisco de Azeredo ${ }^{13}$ deixou transparecer a sua insatisfação argumentando:

... a falta de cômodos no Hospital de Caridade é uma grande calamidade! Pelo abandono que ficam miseravelmente em seus ranchos de palha pelos subúrbios da cidade, quando já não podem esmolar e não poucos casos os que morrem à míngua em seus próprios sítios ou agregados, deixando isolada sua misérrima família alguns pobres lavradores (AHEG, caixa 247).

As crises alimentícias ${ }^{14}$, tão comuns na província, obrigavam à redução do atendimento, a exemplo do que ocorreu em 1860, quando os administradores do nosocômio se viram obrigados a reduzir o número de leitos a 12 (Memórias Goianas, no 9, op. cit., p. 44). A falta de camas e de espaço, as péssimas condições de higiene, a inadequada localização das enfermarias e os parcos recursos contribuíram de alguma forma para o aumento da mortalidade nas dependências do hospital, chegando a atingir 36,8\% no ano de 1880, como pode ser observado no Quadro 2. Para o presidente de 
Quadro 2

Movimento das enfermarias do

Hospital de Caridade São Pedro de Alcântara, I829-1880

\begin{tabular}{|c|c|c|c|c|}
\hline Ano & Entraram & $\begin{array}{c}\text { Curados ou } \\
\text { em } \\
\text { tratamento }\end{array}$ & Faleceram & $\begin{array}{c}\text { Taxa de } \\
\text { mortalidade (\%) }\end{array}$ \\
\hline 1829 & 84 & 12 & 14 & 16,6 \\
\hline 1836 & 95 & 81 & 14 & 14,7 \\
\hline 1837 & 121 & 110 & 11 & 9,0 \\
\hline 1846 & 40 & 31 & 9 & 22,5 \\
\hline 1847 & 51 & 37 & 14 & 27,4 \\
\hline 1848 & 66 & 44 & 22 & 33,3 \\
\hline 1849 & 49 & 43 & 6 & 12,2 \\
\hline 1850 & 86 & 65 & 21 & 24,4 \\
\hline 1851 & 76 & 68 & 8 & 10,5 \\
\hline 1852 & 91 & 78 & 13 & 14,2 \\
\hline 1853 & 47 & 38 & 9 & 19,1 \\
\hline 1854 & 125 & 109 & 16 & 12,8 \\
\hline 1855 & 130 & 112 & 18 & 13,8 \\
\hline 1856 & 115 & $?$ & $?$ & $?$ \\
\hline 1857 & 114 & 107 & 7 & 6,1 \\
\hline 1858 & 124 & 108 & 16 & 12,9 \\
\hline 1859 & 109 & 97 & 12 & 11,0 \\
\hline 1860 & 67 & 57 & 10 & 14,9 \\
\hline 1868 & 129 & 92 & 37 & 29 \\
\hline 1869 & 111 & 87 & 24 & 22,0 \\
\hline 1870 & 106 & 82 & 24 & 22,6 \\
\hline 1871 & 121 & 88 & 33 & 27,2 \\
\hline 1872 & 145 & 116 & 29 & 20,0 \\
\hline 1873 & 171 & 141 & 30 & 17,5 \\
\hline 1874 & 135 & 99 & 36 & 26,6 \\
\hline 1875 & 117 & 87 & 30 & 25,6 \\
\hline 1876 & 118 & 96 & 22 & 18,6 \\
\hline 1878 & 103 & 88 & 15 & 14,5 \\
\hline 1879 & 104 & 78 & 26 & 25,0 \\
\hline 1880 & 95 & 60 & 35 & 36,8 \\
\hline
\end{tabular}

Fontes: Jornal Matutina Meiapontense (CD-ROM), 7.8.1830, pp. 234-5; Memórias Goianas $\mathrm{n}^{\circ} 3$; $\mathrm{n}^{\circ} 4$ (1845-1849), 1996; n 5 (1850-1852), 1996; n 7 (1856-1859), 1997; no 8 (1859-1863), 1997; no 9 (1862-1863), 1998; no 10 (1864-1869), 1998; $\mathrm{n}^{\mathrm{o}} 11$ (1870-1874), 1999; no 12 (1875-1879), 1999; nº $13(1880-1881), 2001 ; \mathrm{n}^{\mathrm{o}} 14$ (1882-1889), 2001. 
província, Eduardo Olímpio Machado ${ }^{15}$, tal circunstância não devia ser atribuída à falta de zelo ou à imperícia do facultativo encarregado da enfermaria. Na sua opinião, os verdadeiros responsáveis eram os próprios doentes, que buscavam tratamento já no último período da doença, quando elas já se haviam tornado crônicas (Memórias Goianas, no 5, op. cit., p. 59-60). Parece que este governante adotou em seu discurso o ponto de vista do doutor Azeredo, que em sua tese defendia a idéia de que:

... o certo é que dos hospitais muitos têm saído perfeitamente curados, e se porventura o número de mortos parece espantoso, é porque senão reflete que nestes estabelecimentos trata-se um grande número não tanto pelos receios destas casas, como desleixo próprio da classe pobre, de sorte que muitos vão já mandados moribundos, para livrarem-se do trabalho da inumação e algumas vezes mesmo mortos (Azeredo, 1844, p. 13).

O temor do nosocômio por parte da população foi ressaltado em inúmeros estudos que analisaram as organizações assistenciais no Brasil. A circunscrição da medicina e suas péssimas condições de funcionamento fortaleceram essa má impressão. Geralmente, os languentos procuravam amparo hospitalar apenas em último caso, na falta de alguém que os tratasse em casa. Além disso, a perspectiva do internamento e o longo tempo da terapêutica representavam o isolamento do enfermo de sua família, o que acabava incitando a fuga de muitos deles, a exemplo de Francisco Dionísio, que, estando quase são, se evadiu do São Pedro de Alcântara (AHEG, livro 202, p. $12 \mathrm{v})$. O mesmo temor encontrava-se presente entre os eivados do Hospital Militar da capital, conforme as informações do pseudônimo Cuiabano Philantropo: "há dois dias um soldado às ordens do Sr. Vice-Presidente foi atacado de uma vertigem, e logo que cobrou os sentidos, disse em voz suplicante - 'Sr. Vice-Presidente, eu não quero ir para o hospital nem a bordoada'" (Matutina Meyapontense, 1.7.1830, pp. 170-1).

No decorrer dos anos, o nosocômio recebeu visitas encarregadas de fiscalizar suas instalações, o funcionamento e as condições do atendimento prestado. Cabia à Câmara Municipal nomear comissões integradas por cidadãos probos, para inspecionar prisões e estabelecimentos públicos de caridade, conforme o artigo 56 da lei de $1^{\circ}$ de outubro de 1828.

Por meio do jornal Matutina Meyapontense foi possível verificar alguns pontos tratados nos relatórios elaborados pelos inspetores nos anos de 1830 e 1833. Na primeira vistoria, os visitadores, além de ressaltar que a instituição não possuía verba para prestar o auxílio necessário aos enfermos, atentaram para a inadequação do local do edifício, uma vez que o prédio apresentava aspecto úmido e fétido, por avizinhar-se a um açougue e ao rio Vermelho. Em relação aos 
utensílios, indicou que se substituíssem as bacias de barro pelas de pó de pedra ou arame (Matutina Meyapontense, 30.10.1830, pp. 381-2).

A falta de cômodos para os mazelentos e a inconformidade do sítio onde encontrava-se edificado o prédio também foram ressaltadas pela segunda comissão de visita:

... tendo de um lado o rio Vermelho próximo aos seus alicerces, de outro a capela de Nossa Senhora do Carmo, na qual sepultam-se muitos cadáveres, e no fundo o açougue impregnado de podridões, resultando destas proximidades a exalação de miasmas, que corrompem o ar, aumentam as enfermidades antigas, e ocasionando novas (Matutina Meyapontense, 30.11 .1833 , p. 393)

Os soldados, internados por ocasião da inspeção, queixaramse da impossibilidade de continuar o uso dos remédios aplicados, uma vez que faltavam farinha e pão nas suas comidas. Provavelmente o governo não estava repassando para o estabelecimento a verba para alimento compatível a cada um dos militares.

Os maiores problemas concentravam-se nas enfermarias dos pobres, que careciam de asseio e utensílios. Além disso, o piso de chão batido necessitava de assoalho, e havia "absoluta necessidade de se construir uma latrina para despejo das fezes humanas, que se vem espalhadas pelo pátio vizinho" (Matutina Meyapontense, 30.11.1833, p. 393).

As enfermarias acolhiam os pacientes em camas ou no chão, o que acontecia muitas vezes, em decorrência da falta de leitos. Muitas pessoas traziam de casa esteiras, que serviam para recostar o corpo e muitas vezes de mortalha. Ao longo dos anos, os administradores investiram na infra-estrutura do edifício, suprindo-o de água e esgoto. Levantaram-se os alicerces e muros, consertaram-se as paredes e tetos e, segundo o presidente de província Luiz de Camargo Fleury, construiu-se um maior número de leitos (Memórias Goianas, no 3, op. cit., pp. 109-10). Tais benfeitorias devem ter ido literalmente por água abaixo com a enchente do rio Vermelho no ano de 1838 :

... o Hospital de Caridade São Pedro de Alcântara foi todo inundado; caíram seus muros e algumas paredes, ficando todas arruinadas e perderam-se drogas medicinais da botica da casa, alguma roupa destinada para os enfermos, mas salvaram-se todos os enfermos, que foram recolhidos na casa do boticário Vicente Moretti Foggia ${ }^{16}$ (Borges, 1984, pp. 39-40).

Muitos medicamentos foram levados pelas enxurradas, bem como livros e papéis contábeis. Os enfermados foram transferidos para outro local e, como boa parte deles recebia atendimento em casa, nada sofreram (Memórias Goianas, n 3, op. cit., p. 149). 
O que fica patente nos relatórios de inspeção dos administradores e de saúde é que o grande incômodo do hospital era sua localização: "fundado, baixo, na margem direita do rio Vermelho, e contíguo à igreja da Senhora do Carmo, onde se enterram muitos corpos, que não pode deixar de se achar ali o ar impregnado de partículas nocivas" (Memórias Goianas, no 4, op. cit., p. 133).

A falta de espaço no terreno para a ampliação do edifício constituía outro obstáculo para melhorar o atendimento. Foram feitas várias tentativas, por meio de concessão de verbas e doações de particulares, de transferi-lo para outra área. Porém, por causa da prioridade da construção do cemitério público, dos desvios de dotações e das várias irregularidades contábeis, a mudança inviabilizou-se.

As teorias miasmáticas encontraram grande vigor nos discursos dos governantes de Goiás. Até a última parte do século XIX, no campo da medicina, dominava o princípio segundo o qual surtos epidêmicos de doenças infecciosas eram causados pelo estado da atmosfera. As condições sanitárias geravam um estado atmosférico que acabava por causar doenças (Rosen, op. cit., p. 211). Assim, criou-se uma certa mentalidade preventiva que passou a nortear as ações públicas, a partir da observação de que certos tipos de doenças ocorriam com mais freqüência - bem como várias epidemias e males contagiosos - como conseqüência da falta de higiene. Para o doutor Azeredo (op. cit., p. 16), na escolha de um local salubre visando a edificação de um hospital próximo à cidade, devia-se

... estudar a natureza do terreno, a disposição de suas camadas, sua inclinação e elevação, as águas que o regam, as espessuras das matas, suas distâncias, a elevação das serras que o avizinham, assim como as proximidades dos pântanos e das exalações infectas de certos fabricos, a desfavorável direção dos ventos ou sua salubridade e freqüência, as neblinas, a intensidade e a freqüência dos vapores elétricos.

Ainda que o local destinado ao edifício apresentasse inconvenientes, estes podiam ser corrigidos mediante as indicações dos peritos.

No interior dos nosocômios, a ordem dos discursos aconselhava que se substituíssem os pisos de corte pela pedra chata. Rebocar, forrar, pintar, caiar paredes, tetos e madeiramentos era vestir uma couraça contra o miasma. As enfermarias deveriam ser caiadas pelo menos uma vez por ano, lavadas todos os meses, arejadas e fumigadas todas as vezes que fossem determinadas pelo médico (AHEG, caixa 401). Limpar significava, mais do que lavar, drenar. O essencial era assegurar o escoamento, a evacuação da imundície (Corbin, 1987).

Desaconselhava-se a multiplicação dos andares em uma instituição de saúde, já que os pisos superiores possuíam menor salubridade. 
No Hotel Dieu de Paris ${ }^{17}$, por exemplo, a mortalidade se apresentava mais acentuada nos pavimentos superiores que nos inferiores (Azeredo, op. cit., p. 22).

Secar a cidade por meio de drenagem de pântanos pestilenciais, situados em suas vizinhanças, inscrevia-se na ordem do dia. A ventilação constituía, por sua vez, o eixo da estratégia higienista. Mais importante ainda do que drenar a imundície, era assegurar a circulação do fluido aéreo. Nesse sentido o aerismo neo-hipocrático encontrava sua justificativa teórica (Corbin, op. cit., pp. 121-7).

Durante o período em que exerceu o cargo de inspetor de saúde, o doutor Azeredo recomendou a remoção do lixo existente em vários lugares da cidade, a limpeza das sarjetas da praça do chafariz e do açougue, a desobstrução dos bueiros e a inspeção rigorosa dos gêneros alimentícios vendidos no mercado, medidas prioritárias que dependiam de uma atuação mais enérgica por parte da Câmara Municipal. Interferências maiores, de competência do governo provincial, também se faziam necessárias, como a destruição de alguns prédios visando a facilitação da circulação do ar, a construção do cais da Lapa e a mudança do curso do rio Uru para uma das cabeceiras do rio Vermelho (Memórias Goianas, nํㅜ 13, 2001, p. 28).

Na segunda metade do século XIX, os médicos particularmente inseridos na categoria dos profissionais liberais encontraram nas cidades o espaço propício para aplicar seus conhecimentos e efetivar sua atuação. Como um dos segmentos da intelectualidade, empenhavamse na tarefa de ordenar aquilo que era visto como desordem, transformando a cidade num espaço civilizado (Engel, 1989).

Em sintonia com as teorias aeristas, os administradores do hospital providenciaram a compra de vidros, no Rio de Janeiro, para envidraçar as janelas do recinto. Presas por cadeados, elas seriam abertas todas as vezes que se fizesse necessária a renovação do ar. A ausência de vidros nas janelas das casas residenciais e dos prédios públicos era comum em Goiás. O viajante austríaco John Emanuel Pohl ${ }^{18}$ (1951, p. 327) mencionava em seu diário que, na falta de vidraças, as janelas eram cobertas com panos ou mica, minério que se encontrava em grande quantidade na região.

A construção térrea do hospital possuía salas grandes e certamente frias, pela proximidade do rio. Muitas das ampliações de espaço foram feitas a partir de remodelações, como foi mencionado anteriormente. Aproveitavam-se também áreas inabitadas como porões e sótãos. Localizada à beira do rio, a instituição sofria ainda com o ataque de inúmeros insetos. Como inexistiam banheiros, junto ao leito do enfermo havia um escarrador e um urinol (AHEG, caixa 0010), que não deveriam ser bem utilizados. As paredes e o chão eram freqüentemente usados como local apropriado para realização das necessidades fisiológicas, o que provocava um odor insuportável. 
Tomava-se banho, ao que tudo indica, somente aos sábados, quando se fazia a troca de roupa dos enfermos e das camas (AHEG, caixa 401). O capim dos colchões deveria ser trocado quando estivesse moído, ou se tivesse abrigado enfermo com doença grave, sobretudo contagiosa. Inexistia a separação nas enfermarias para tuberculosos, idosos e portadores de moléstias transmissíveis.

Algumas divergências podem ser averiguadas nos discursos dos administradores que inspecionaram o hospital. O presidente Antero Cícero $^{19}$, que o visitou no ano de 1873 , ficou impressionado com a regularidade do serviço prestado, com a limpeza e a economia do lugar (Memórias Goianas, no 11, 1999, pp. 312-3). Em 1879, o presidente Aristides de Souza Spínola ${ }^{20}$, além de reclamar do lugar onde o edifício estava assentado, criticou a pequenez dos cômodos e a falta de asseio. Denotou ainda a infração dos preceitos higiênicos, denunciando a transformação do pequeno quintal existente em esterquilíno (Memórias Goianas, nํ 12, op. cit., p. 245).

Os mapas de dietas do hospital revelam gastos com a compra de milho para galinhas, informação que denuncia a presença de galinheiros nos fundos do terreno, justificando em parte a existência do referido monturo.

O São Pedro de Alcântara começou a esboçar os princípios dos hospitais modernos orientados especificamente para a cura no início do século XX, graças às reformas realizadas sob a administração das irmãs dominicanas.

*Este artigo constitui o quinto capítulo da tese de doutorado Alimentação, saúde e doenças em Goiás no século XIX, que desenvolvo presentemente no Programa de PósGraduação da UnespFranca, financiada pela Capes, sob a orientação da professora doutora Ida Lewkowicz.

\section{Considerações finais}

O Hospital de Caridade São Pedro de Alcântara contribuiu, na medida do possível, para o bem-estar social em Goiás durante o século XIX. Em uma cidade em que as condições sanitárias eram deficientes e as doenças eram comuns, somente essa instituição oferecia à população alguma forma de assistência. Porém, por sua condição financeira instável, estava desprovido de condições para ampliar seu atendimento. Nesse período, a idéia de atendimento hospitalar vinculava-se à caridade, uma vez que os órgãos públicos não se viam necessariamente obrigados a custeá-lo. Tal realidade relaciona-se à tradição religiosa do Brasil, na qual o catolicismo teve forte influência. A escravidão, por sua vez, deu o tom de como deveria ser a caridade paternalista. 


\section{NOTAS}

${ }^{1}$ Durante o século XVII, o hospital vinha em segundo lugar, bem distanciado da igreja. As festas religiosas davam mais prestígio à irmandade do que ao tratamento dos doentes. Um funeral bem organizado ou uma missa brilhante traziam mais irmãos novos e mais legados à irmandade do que os cuidados médicos a todos os mendigos e escravos famintos. No século XVIII, o hospital estava atrás das outras atividades da filantropia social (Russel-Wood, 1981).

${ }^{2}$ Raymundo José da Cunha Mattos nasceu em Portugal em 1776. Chegou a Goiás, como governador das Armas, no ano de 1823. No mesmo ano seguiu para o norte do território, a pedido do imperador, com o objetivo de apaziguar conflitos decorrentes do processo de independência do Brasil — a população da parte setentrional da província não reconhecia o poder de d. Pedro I e vislumbrava a implantação de uma república. Dessa empreitada nasceu a Corografia histórica da província de Goiás (Mattos, 1979), obra repleta de informações históricas, sociais, culturais e geográficas.

3 Joaquim Alves de Oliveira (1770-1851) é considerado o 'pai da imprensa goiana', por ter criado o primeiro jornal da província, a Matutina Meiapontense, no ano de 1830. Era dono da maior propriedade agrícola da região, o engenho São Joaquim.

${ }^{4}$ Luiz Gonzaga de Camargo Fleury (1793 a 1846) foi o quinto presidente da província de Goiás (20.3.1837 a 4.9.1839).

5 "Depois das festividades da comemoração do dia de São Pedro de Alcântara, estarão três membros da Junta do hospital para receber as esmolas. Em todos os outros dias do ano se colocará à porta do hospital uma caixa para as esmolas, fixadas com duas chaves, as quais serão guardadas por dois Membros da Junta, que irão abri-las aos sábados. Esta caixa será recolhida todas as noites pelo Diretor, ou enfermeiro" (AHEG, caixa 0010, título VI, artigo III).

${ }^{6}$ José de Assis Mascarenhas foi o sexto presidente da província de Goiás (4.9.1839 a 14.10.1845).

${ }^{7}$ O médico Theodoro Moraes (1816-1897) defendeu a tese intitulada O estrangulamento das hérnias entero-epiplóicas e os meios de curar, na Faculdade de Medicina do Rio de Janeiro, no ano de 1842. Como primeiro doutor goiano formado na academia, desde que retornou à sua cidade natal assumiu o cargo de médico do hospital São Pedro de Alcântara. Membro de família abastada que participava ativamente das decisões administrativas da província, Moraes decidiu clinicar gratuitamente, ciente da pobreza da comunidade. O governo provincial, todavia, estipulou o seu vencimento em seiscentos mil-réis anuais. Posteriormente engajou-se na vida política, assumindo os cargos de presidente e vice-presidente da província de Goiás em breves períodos. Participou ativamente dos projetos de reformas do edifício do São Pedro de Alcântara e da construção do cemitério público da cidade. Após inúmeros estudos, decidiu "marcar para a construção do cemitério o lugar que fixa alguns passos além das últimas casas da rua do Retentém, que reunia as condições de calor indispensáveis a pronta dissolução dos cadáveres". Atuou também como professor no Liceu de Goiás, escola de nível secundário criada em 1846, ministrando as disciplinas de história e geografia (Martins, 1983, p. 42).

${ }^{8}$ Antônio de Pádua Fleury foi o oitavo presidente da província (19.2.1848 a 11.6.1849). Sua administração foi marcada por diversas benfeitorias visando embelezar a cidade de Goiás: calçou diversas ruas, construiu parte do cais do rio Vermelho (a fim de resguardar o setor central da cidade contra futuras enchentes) e iluminou a querosene as ruas principais.

${ }^{9}$ Joaquim Ignácio de Ramalho, barão de Ramalho, foi o sétimo presidente da província (14.10.1845 a 19.2.1848). Em seu governo foi criado o Liceu de Goiás.

${ }^{10}$ Denominam-se bens de raiz aqueles que não se podem arredar do solo, sob pena de fragmentação, por serem por ele constituídos ou por estarem a ele incorporados (prédios urbanos e rurais etc.).

${ }^{11}$ José Martins Pereira de Alencastre governou a província de 22.4.1861 a 26.6.1862. Além de implementar o ensino secundário e a obrigatoriedade do ensino primário, promoveu a construção de cemitérios nas localidades goianas, visando evitar a realização de sepultamentos no interior ou nas imediações das igrejas (Alencastre, 1978). Alencastre marcou sua passagem por Goiás escrevendo, em 1863, a obra intitulada Anais da província de Goiás.

${ }^{12}$ A partir de 1830 a população da província aumentou, estimulada pelos rendimentos da pecuária: 79 mil em 1849 ; 122 mil em 1856; 133 mil em 1861; 149 mil em 1872; 227 mil em 1890; 255 mil em 1900.

13 O médico goiano Francisco Antônio de Azeredo (1815-1884) defendeu a tese intitulada Algumas considerações gerais acerca da importância e bigiene pelos hospitais civis, na Faculdade de Medicina do Rio de Janeiro, em 1845. Foi o primeiro estudante bolsista da província. Por meio da resolução no 10 do ano de 1836, a Assembléia Legislativa autorizou as Câmaras Municipais a despender cada qual trezentos mil-réis anuais com um aluno natural da província que se interessasse em freqüentar o curso da Academia Médica Cirúrgica, estabelecida no Rio de Janeiro. Parece que a consagração de sua carreira verificou-se no âmbito militar durante a Guerra do Paraguai, quando ocupava o cargo de primeiro-médico do Hospital Militar. Assentou-se inicialmente como praça, em 1852 como alferes cirurgião-ajudante, alcançando por antiguidade o posto de major cirurgião-mor de brigada em 1866. Foi professor do Liceu de Goiás, ministrando as disciplinas de retórica e poética.

${ }^{14}$ Ainda que surtissem alguns efeitos, as ações administrativas, apenas paliativas, se mostraram ineficazes no combate às crises alimentícias em Goiás durante o século XIX. A escassez, a carestia e por vezes a fome declarada afligiram cronicamente aquela sociedade. A ação dos atravessadores, a sazonalidade climática, a falta de estímulo à agricultura, a ausência de técnicas, a falta de braços, os altos impostos, as dificuldades de comércio e transporte são fatores que se cruzam e entrecruzam para justificar aquela realidade. 
${ }^{15}$ Eduardo Olímpio Machado foi o nono presidente da província (11.6.1849 a 10.7.1850). Em seu governo foi suspensa a vacina contra bexigas (varíola), pois ele a considerava prejudicial à saúde da população.

${ }^{16}$ Vicente Moretti Foggia (1801-1892) chegou ao Brasil no início da década de 1830, fugindo da polícia. No ano de 1821, época em que cursava medicina, participou ativamente de uma revolta carbonária que eclodiu no Piemonte. Ao longo dos séculos XVIII e XIX, o difícil acesso ao remoto território de Goiás serviu de abrigo e esconderijo para diversos fugitivos da Justiça. Mesmo não tendo concluído o curso de medicina, garantia a sua sobrevivência no exercício das artes de curar. Em 1836 foi nomeado boticário do São Pedro de Alcântara. Três anos depois, persistindo a falta de médicos, o italiano foi também encarregado do curativo dos doentes do hospital e dos presos da cadeia. Foggia assumiu inicialmente o cargo de boticário, depois de cirurgião e médico, na ausência de facultativos. Exerceu também o cargo de inspetor de higiene pública. No Liceu de Goiás ministrou as matérias de geografia e aritmética.

${ }^{17}$ O Hôtel-Dieu de Paris (criado na segunda metade do século VII) foi tomado como protótipo de tudo quanto os hospitais deveriam evitar na sua gestão. Apesar das enormes dimensões, os doentes se amontoavam às centenas em cada enfermaria, chegando a dispor oito deles em cada cama coletiva (Antunes, op. cit., p. 142).

${ }^{18}$ O médico austríaco John Emmanuel Pohl (1782-1834) viajou pelo Brasil durante quatro anos (1818-1821), visitando as províncias de Minas Gerais, Pará, Mato Grosso e Goiás. Nesta última permaneceu por dois anos. Em seu diário de viagem abundam informações sobre economia, cultura, sociedade e as patologias reinantes nas regiões visitadas.

${ }^{19}$ Antero Cícero de Assis foi o vigésimo quarto presidente da província (25.4.1871 a 22.7.1878).

${ }^{20}$ Aristides de Souza Spínola foi o vigésimo sexto presidente da província (15.3.1878 a 1.2.1881).

\section{ABREVIATURAS}

AHEG - Arquivo Histórico do Estado de Goiás

SCFSD - Sociedade de Cultura Frei Simão Dorvi (cidade de Goiás)

UCG - Universidade Católica de Goiás

\section{FONTES CONSULTADAS}

\section{MANUSCRITAS}

Regulamento para o Hospital de Caridade São Pedro de Alcântara da cidade de Goiás. s. d. AHEG. Caixa 0010.

Correspondência do e para o comandante das Armas em Goiás, Raymundo da Cunha Mattos. AHEG. Livro 119.

Conta corrente do Hospital de Caridade São Pedro de Alcântara. 1826. Tesouraria da Fazenda. AHEG. Livro $n^{\circ} 145$.

Registro da Presidência da província à administração do Hospital São Pedro de Alcântara. 1836-1862. AHEG. Livro 202.

Delegacia do Corpo de Saúde de Goiás. 1875. AHEG. Caixa 247.

Regulamento para o Hospital de Caridade São Pedro de Alcântara da cidade de Goiás. 1835. AHEG. Caixa 401.

Livro para lançamento de todos os medicamentos fornecidos aos enfermos do Hospital da Caridade de Goiás. SCFSD.

\section{IMPRESSAS E FAC-SÍMILE}

Coleção das leis do Império do Brasil. Rio de Janeiro, Tipografia Nacional. 1850

Memórias Goianas, nำ 3. Relatórios políticos, administrativos, econômicos, sociais etc. dos governos da província de Goiás (1835-1843). Goiânia, UCG. 1986 
Memórias Goianas, n⿳ำ 4. Relatórios políticos, administrativos, econômicos, sociais etc. dos governos da província de Goiás (1845-1849). Goiânia, UCG. 1996

Memórias Goianas, n⿳ำ 5 . Relatórios políticos, administrativos, econômicos, sociais etc. dos governos da província de Goiás (1850-1852). Goiânia, UCG. 1996

Memória Goianas, nº 6. Relatórios políticos, administrativos, econômicos, sociais etc. dos governos da província de Goiás (1854-1856). Goiânia, UCG. 1997

sociais etc. dos governos da província de Goiás (1875-1879). Goiânia, UCG. 1999

Memórias Goianas, no 13. Relatórios políticos, administrativos, econômicos, sociais etc. dos governos da província de Goiás (1880-1881).Goiânia, UCG. 2001

\section{DIGITALIZADAS}

Matutina Meyapontense. AGEPEL (Agência Goiana de Cultura Pedro Ludovico Teixeira). CD-ROM. 1830-1834

A Informação Goyana. AGEPEL (Agência Goiana de Cultura Pedro Ludovico Teixeira).

CD-ROM. 1917-1935

\section{REFERÊNCIAS BIBLIOGRÁFICAS}

Alencastre, José Martins

Pereira de

1978

Antunes, José Leopoldo

Ferreira

1991

Azeredo, Antônio

Francisco de 1844

Bertolli Filho, Cláudio 2000

Borges, Humberto

Crispim

1984

Canezin, Maria

Tereza et al.

1994

Corbin, Alain

1987

Curado, S. Fleury 1989

Engel, Magali 1989

Ferreira, Joaquim

Carvalho

1980

Foucault, Michel 1994
Anais da província de Goiás.

Brasília, Sudeco/Governo de Goiás.

Hospital. Instituição e história social.

São Paulo, Letras e Letras.

Algumas considerações gerais acerca da importância da higiene dos hospitais civis. Tese de doutoramento, Faculdade de Medicina do Rio de Janeiro, Rio de Janeiro. (mimeo.)

'Cinco séculos de enfermidades'.

Ciência Hoje, vol. 28, no 165 , pp. 34-41.

O pacificador do Norte.

Goiânia, Editora do Cerne.

A escola normal em Goiás.

Goiânia, UFG.

Saberes e odores.

São Paulo, Companhia das Letras.

Memórias históricas.

Goiânia, s. n.

Meretrizes e doutores. Saber médico e prostituição no Rio de Janeiro (1840-1890). São Paulo, Brasiliense.

Os presidentes e governadores de Goiás. Goiânia, UFG.

O nascimento da clínica.

Rio de Janeiro, Forense Universitária. 
Foucault, Michel 1987

Freitas, Lena Castello

Branco Ferreira de 1999

Funes, Eurípedes

Antônio

1986

Geremek, Bronislaw 1986

Leal, Víctor Nunes 1975

Leite, Ilka Boaventura 1996

Lyda, Massako 1994

Martins, Zildete Inácio de Oliveira

1983

Mattos, Raymundo 1979

Moraes, Cristina de

Cássia Pereira de Moraes 1995

Pohl, Jonh Emannuel 1951

Rabelo, Danilo

1997

Rosen, George 1994

Russel-Wood, A. J. R. 1981

Salles, Gilka Vasconcelos

Ferreira de 1999

Weber, Beatriz Teixeira 1999
Vigiar e punir.

Petrópolis, Vozes.

'Goiânia: lócus privilegiado da saúde'. Em Lena Castelo Branco Ferreira de Freitas (org.). Saúde e doenças em Goiás. A medicina possível, p. 273. Goiânia, UFG.

Goiás 1800-1850: um periodo de transição da mineração à agropecuária. Goiânia, Editora da UFG.

A piedade e a forca. História da miséria e da caridade na Europa. Lisboa, Terramar.

Coronelismo, enxada e voto. O município e o regime representativo no Brasil. São Paulo, Alfa-Ômega.

'Condições de vida, condições de produção'. Em Antropologia da viagem, p. 63-127. Belo Horizonte, UFMG.

Cem anos de saúde pública. A cidadania negada.

São Paulo, Unesp.

A participação de Goiás na Guerra do Paraguai (1864-1870).

Goiânia, UFG.

Corografia histórica da província de Goiás. Goiânia, Sudeco.

As estratégias de purificação dos espaços na capital da província de Goiás (1835-1843). Dissertação de mestrado, Instituto de Ciências Humanas e Letras da Universidade Federal de Goiás, Goiânia. (mimeo.)

Viagem no interior do Brasil, vol. 1.

Rio de Janeiro, Instituto.

Os excessos do corpo. A normatização dos comportamentos na cidade de Goiás (1822-1899). Dissertação de mestrado. Faculdade de Ciências Humanas e Filosofia, Universidade Federal de Goiás, Goiânia. (mimeo.)

Uma bistória da saúde pública.

São Paulo, Hucitec.

Fidalgos e filantropos. A Santa Casa de Misericórdia da Babia, 1550-1755.

Brasília, UnB.

'Saúde e doenças em Goiás (1826-1930)'.

Em Lena Castelo Branco Ferreira de Freitas (org.). Saúde e doenças em Góias. A medicina possível, pp. 63-127, Goiânia, UFG.

As artes de curar. Medicina, religião, magia e positivismo na República Rio-Grandense - 1889-1928. Santa Maria/Bauru, UFSM/Edusc. 